\title{
Soixante ans de recherche sur la lipolyse enzymatique des corps gras à Marseille
}

Frédéric CARRIÈRE

Laboratoire d'enzymologie interfaciale et de physiologie de la lipolyse, CNRS UPR 9025,

31 chemin Joseph Aiguier,

13402 Marseille cedex 20, France

<carriere@ibsm.cnrs-mrs.fr>

\begin{abstract}
Lipolytic enzymes have been associated with the city of Marseille ever since the 1940s. At that time, the biochemists established tight links with the Marseille School of Chemistry for investigating fat-splitting by enzymes, particularly the hydrolysis of triglycerides by lipases. Several important milestones on lipase research are associated with this long standing collaboration, from the molecular aspects of lipases to their physiological roles and their various medical and industrial applications. This story will be reviewed here through several highlights on pancreatic and gastric lipase research. Pancreatic lipase, which was for long the only lipase available for biochemical studies, still remains an attractive enzyme with the development of lipase inhibitors for obesity treatment. It is also used for enzyme replacement therapy in case of exocrine pancreatic insufficiency. Novel pancreatic lipaserelated proteins have been identified and their physiological roles now extend from fat digestion to lipoprotein metabolism, lipid signaling and innate immunity.
\end{abstract}

Key words: enzymology, enzymatic lipolysis, heterogeneous enzyme catalysis, lipase, pancreas, triglyceride
La médaille Chevreul récompense chaque année depuis 1963 une personnalité française et une personnalité étrangère ayant contribué de façon significative au développement des connaissances ou des réalisations industrielles dans le domaine des corps gras. Elle rappelle que c'est en France, grâce aux travaux de Michel Eugène Chevreul (1786-1889), que sont nées la chimie des corps gras et la lipochimie. Je suis très heureux de la recevoir cette année pour mes travaux sur les lipases, ces enzymes qui permettent de digérer les corps gras. Je voudrais à cette occasion rappeler que je suis le cinquième chimiste formé à Marseille à recevoir cette distinction. Pierre Desnuelle (1965), Maurice Naudet (1971), Bernard Entressangles (1983) et Jean Graille (1997) m'ont précédé. Nous avons tous en commun $\mathrm{d}^{\prime}$ avoir travaillé sur les lipases à un moment de notre carrière. Comme la fabrication du savon, l'étude des lipases est ainsi une longue tradition marseillaise initiée il y a plus de 60 ans et reconnue au niveau international.

Lorsque le Professeur Pierre Desnuelle (figure 1) arriva à Marseille en 1943 pour y enseigner la biochimie et prendre la direction du Laboratoire national des matières grasses (futur ITERG, localisé aujourd'hui à Bordeaux), I'industrie des huiles et corps gras était encore importante dans la région marseillaise et la Chambre de commerce et d'industrie l'incita à développer une recherche à l'interface entre la chimie des lipides et la biologie. Ingénieur chimiste de formation, élève du Prix Nobel Victor Grignard à Lyon, Pierre Desnuelle comprit rapidement qu'une bonne connaissance de la physico-chimie était essentielle pour appréhender le mode d'action des enzymes agissant sur des substrats insolubles tels que les huiles. Pour recruter un grand nombre de ses futurs élèves, il se tourna donc naturellement vers l'Ecole supérieure de Chimie de Marseille (figure 2) dirigée par le Professeur Margaillan et qui se trouvait à quelques pas de son laboratoire sur le site de la faculté des sciences de St Charles. $\mathrm{Ce}$ lien avec les élèves de l'Ecole de Chimie (devenue aujourd'hui une composante de l'Ecole Centrale de Marseille) s'est perpétué depuis cette époque et plusieurs d'entre eux ont contribué aux très nombreuses publications sur les lipases issues de la cité phocéenne: Pierre Savary (Promotion 1939), Maurice Naudet (Promotion 1940), Mireille Rovery (Promotion 1945), Louis Sarda (Promotion 1954), Odette Guy-Crotte (Promotion 1957), Gilbert Benzonana (Promotion 1960), Suzanne Maroux (Promotion 1960), Jean Graille (Promotion 1965), Jacques Baratti (Promotion 1966), Gérard Piéroni (Promotion 1966), Robert Verger (Promotion 1966), Gérard Buono (Promotion 1968), Christian Triantaphylidès (Promotion 1969), Georges Langrand (Promotion 1981), Frédéric Carrière (Promotion 1986), Frédéric Fotiadu (Promotion 1987), Franck Marguet (Promotion 1988), Jean-François Cavalier (Promotion 1993), Sylvie Fernandez (Promotion 2005). Cette histoire commune est jalonnée d'étapes importantes dans la description du mode d'action des lipases, depuis leurs aspects moléculaires jusqu'à leur rôle physiologique et à leurs nombreuses applications médicales et industrielles.

\section{Les travaux de pionnier de Pierre Desnuelle sur la lipase pancréatique}

Pierre Desnuelle s'intéresse aux aspects moléculaires de la digestion, poursuivant ainsi le travail de Claude Bernard sur l'action des sucs digestifs, notamment l'action du suc pancréatique sur les matières grasses et les protéines. Le pancréas est alors la principale source d'enzymes et l'étude des enzymes pancréatiques sera au centre de ses projets de recherche pendant 40 ans. Contrairement à Jacques Monod, il ne considère pas les enzymes de la digestion comme plus « naïfs » que ceux impliqués dans les réactions intracellulaires mais comme des modèles permettant de comprendre les processus enzymatiques dans leur ensemble. II est contemporain de grands noms de la biochimie comme Hans Neurath, qui s'intéresse également aux protéases pancréatiques, et Christian Anfinsen, William H. Stein et Standford Moore qui obtiendront tous trois le prix Nobel de Chimie en 1972 pour leurs travaux sur la ribonucléase pancréatique. Pierre Desnuelle sera plus particulièrement reconnu pour ses travaux sur la lipase pancréatique et l'adaptation de la sécrétion des enzymes pancréatiques en fonction du régime alimentaire.

\section{Les lipases utilisées comme outils pour étudier la structure des corps gras}

La première période d'étude des lipases à Marseille sera consacrée à leur utilisation pour élu- 


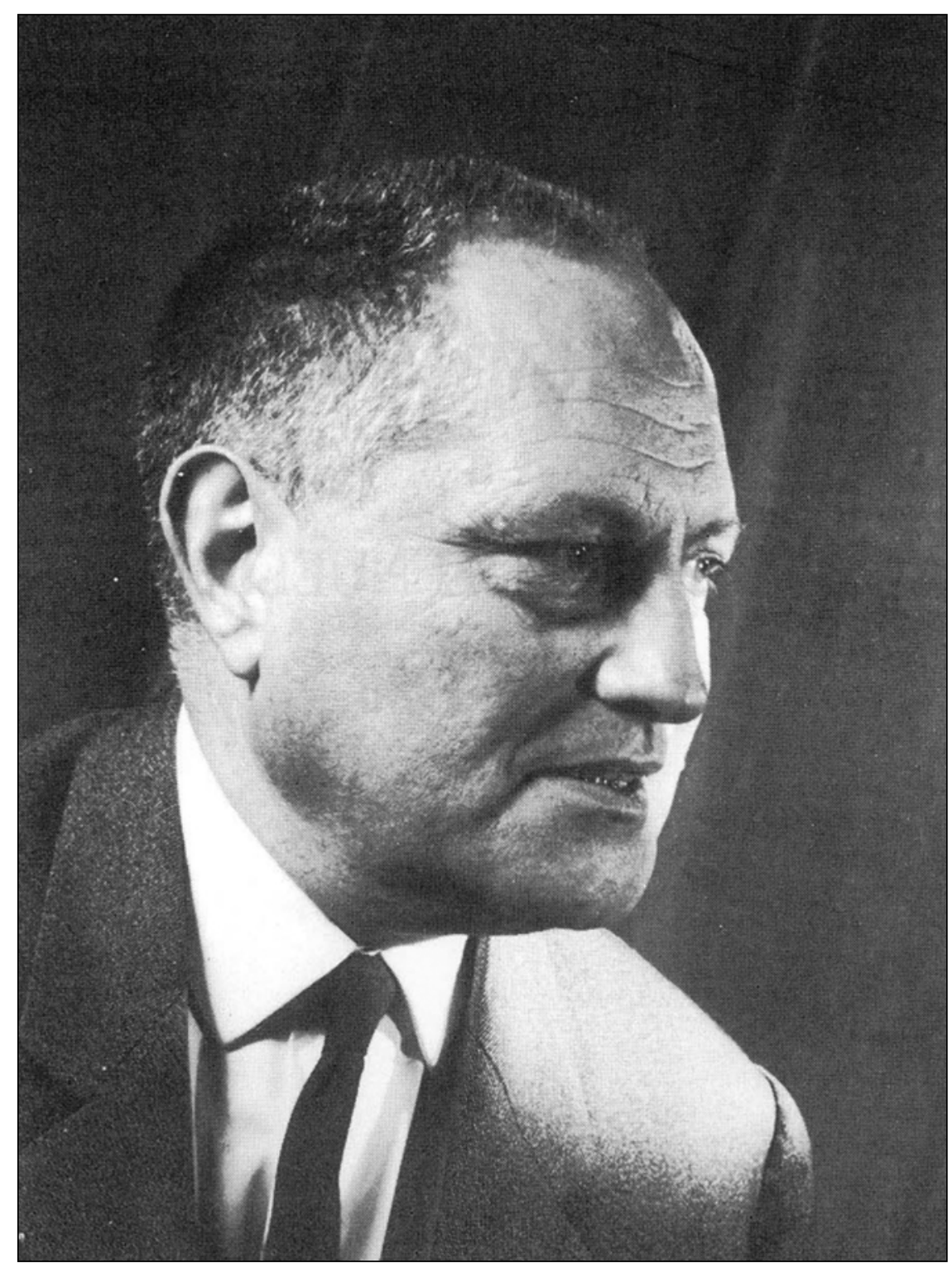

Figure 1. Pierre Desnuelle.

cider, et par la suite modifier, la structure des principaux constituants des corps gras, les triglycérides. Maurice Naudet fut le premier élève de Pierre Desnuelle à passer une thèse de doctorat ès-Sciences physiques en 1947 sur la migration des chaînes acyles entre triglycérides. À cette époque, on savait que les triglycérides étaient des triesters du glycérol et d'acides gras mais on ne savait pas encore s'il existait une distribution particulière des acides gras sur le glycérol. Desnuelle et Naudet pensaient que les acides gras composants les triglycérides n'étaient pas distribués de façon aléatoire sur le squelette à trois carbones du glycérol. Si cela était le cas, on pouvait espérer modifier la distribution de ces acides gras et les propriétés physico-chimiques des triglycérides par interestérification chimique ou enzymatique [1-3]. nombreux travaux réalisés à ce jour sur la spécificité de substrat des lipases et leurs diverses applications dans le domaine de la biotransformation des huiles et corps gras par transestérification enzymatique.

\section{Naissance de l'enzymologie en milieu hétérogène}

L'enzymologie dite «interfaciale» est aujourd'hui un champ de recherche en plein essor car de nombreux enzymes sont impliqués dans des réactions se déroulant aux interfaces, que ce soit dans le monde vivant (membranes cellulaires, métabolisme des lipoprotéines) ou dans des applications industrielles (lessives et lipolyse des taches de graisses sur les tissus, dégradation de la cellulose). Cette enzymologie particulière est cependant largement absente des traités d'enzymologie générale alors que le modèle classique de MichaelisMenten-Henri n'est plus applicable en milieu hétérogène. Lorsqu'on étudie des enzymes, qui comme les lipases sont parfaitement solubles dans l'eau mais agissent à l'interface huileeau, il faut tenir compte du partage de l'enzyme entre la phase aqueuse et la surface des gouttelettes lipidiques. II faut également tenir compte de tous les phénomènes pouvant être liées à cette transition et à la physicochimie de l'interface : changements conformationnels pouvant aller jusqu'à la dénaturation des protéines lors de leur adsorption, effet de la tension superficielle et organisation des lipides à l'interface, accumulation à l'interface des produits de la réaction ou d'autres molécules amphiphiles pouvant agir comme inhibiteurs ou accélérateurs des réactions enzymatiques, etc. Sous l'impulsion de Pierre Desnuelle, les biochimistes marseillais ont très tôt considéré ces paramètres et jeté les bases de l'enzymologie en milieu hétérogène.

Dans la lignée des travaux d'Holwerda et al. [14] et de Schonheyder et Volqvartz [15-17], Sarda (figure 3) et Desnuelle ont tout d'abord montré en 1958 que la lipase pancréatique de porc possédait la particularité de « s'activer à I'interface » huile-eau [18]. Alors que l'enzyme est faiblement active sur un substrat soluble (triglycérides à courtes chaînes à faible concentration), elle multiplie son activité de 2 à 3 ordres de grandeur lorsque le substrat s'agrège et forme une émulsion au-delà de sa limite de solubilité. Les lipases (triacylglycerol hydrolases, EC 3.1.1.3) ont alors été définies comme une famille particulière d'estérases, actives sur un substrat insoluble, les triglycérides, et possédant la propriété cinétique d'activation interfaciale [18]. Cette définition a depuis été revisitée, toutes les lipases ne possédant pas forcément cette propriété [19]. Parmi les diverses hypothèses formulées pour tenter d'expli- 


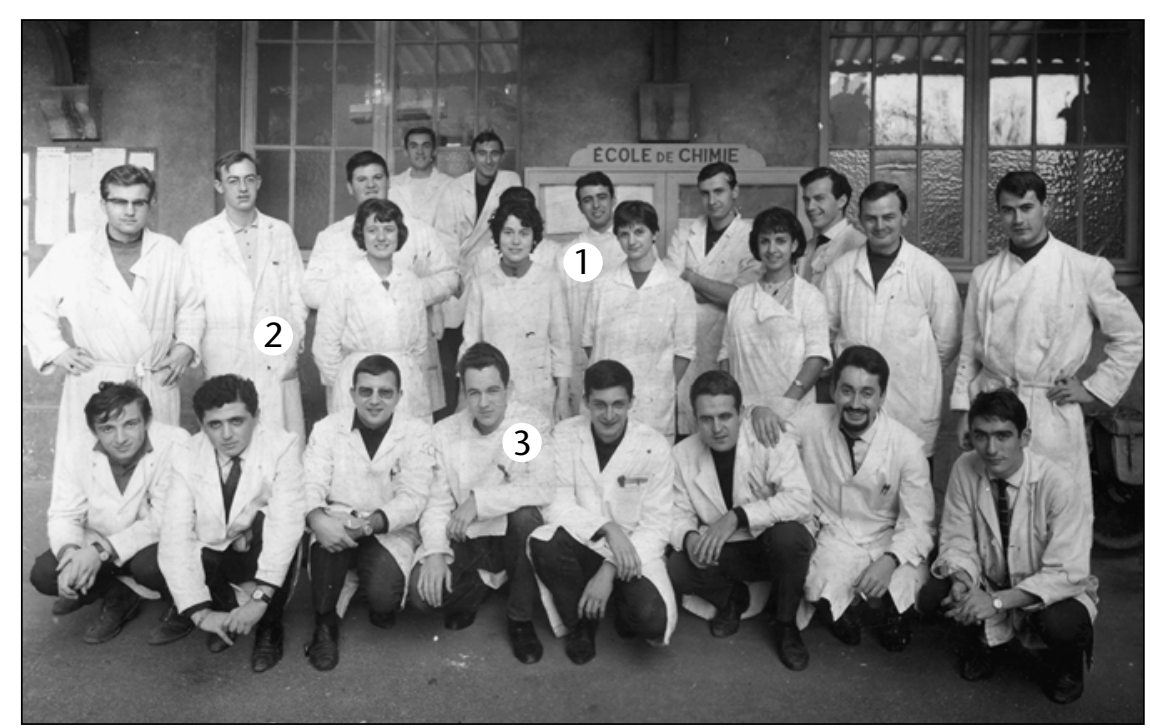

Figure 2. La promotion 1966 de l'Ecole Supérieure de Chimie de Marseille. On peut reconnaître sur cette photo trois élèves qui s'illustreront dans le domaine des lipases : (1) Robert Verger, (2) Gérard Piéroni, (3) Jacques Baratti.

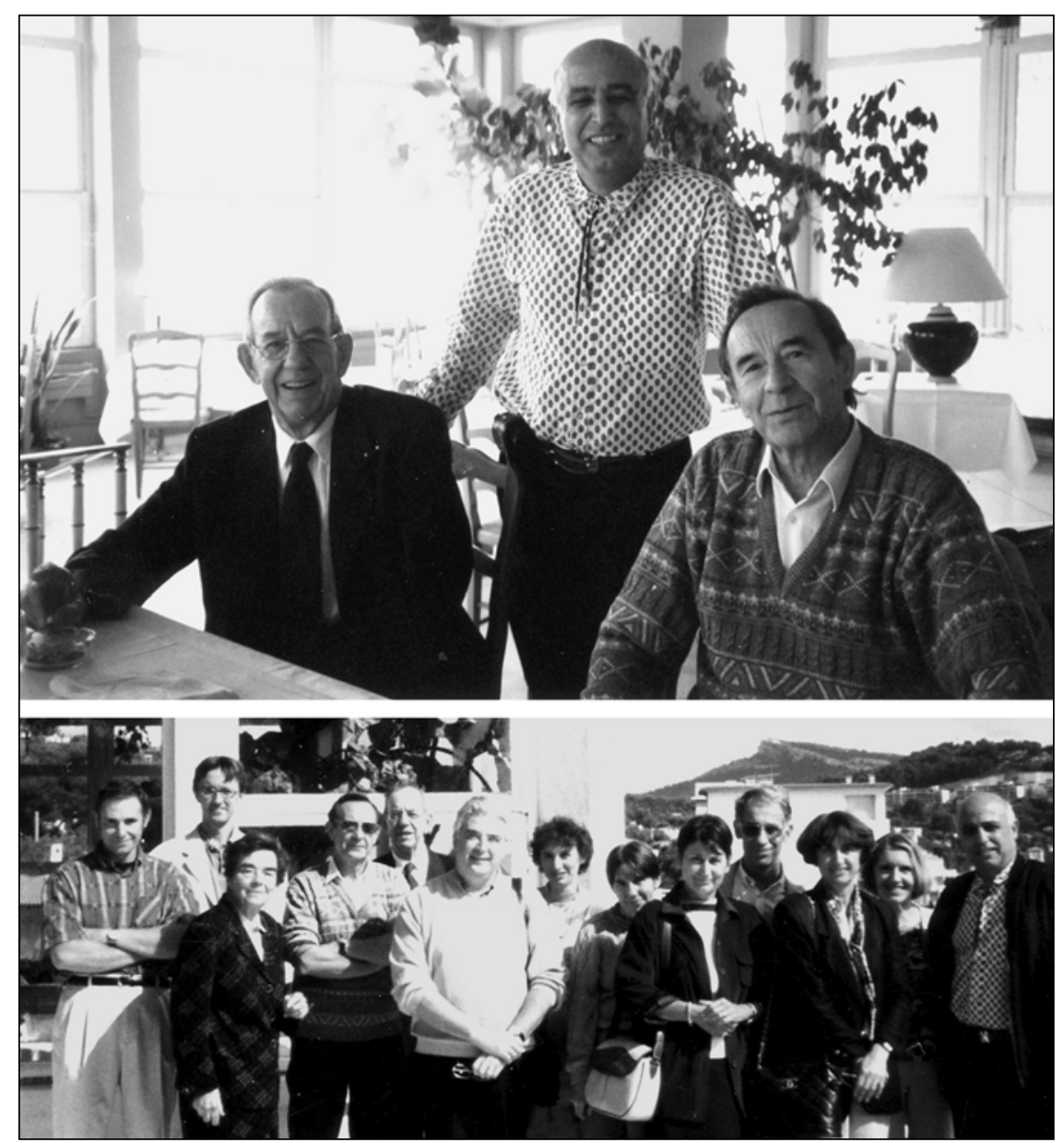

Figure 3. Les "lipasistes" marseillais réunis à Cassis en 1998 pour fêter les 40 ans de l'article sur l'activation interfaciale de la lipase pancréatique [18]. Photo du haut : Gérard De Haas (à gauche), Robert Verger (au centre) et Louis Sarda (à droite); Photo du bas : de gauche à droite, Frédéric Carrière, Herman van Tilbeurgh, Mireille Rovery, Louis Sarda, Gérard De Haas, Alain De Caro, Liliane Dupuis, Catherine Wicker, Josiane De Caro, Claude Rivière, Margarita Ivanova, Francine Ferrato, Robert Verger. quer l'activation interfaciale, Desnuelle et al. ont proposé qu'un changement conformationnel de l'enzyme se produise au contact de I'interface huile-eau [20]. Nous verrons par la suite que les travaux ultérieurs des cristallographes ont soutenus cette hypothèse sans qu'aucun lien formel entre cette propriété cinétique et des changements conformationnels observés dans le cristal ne soit établi à ce jour. Quoi qu'il en soit le phénomène d'activation interfaciale des lipases a été un élément extrêmement stimulant pour la recherche et les travaux sur les lipases qui ont suivis.

En étudiant la lipolyse d'émulsions de triglycérides de tailles variables, Benzonana et Desnuelle montreront en 1965 que la vitesse de la réaction d'hydrolyse des triglycérides par la lipase pancréatique dépend, non pas de la quantité (masse) de substrat, mais de la surface de l'émulsion disponible, et donc du degré d'émulsification du substrat [21]. Ce fut une observation essentielle pour la définition des paramètres importants en enzymologie interfaciale, tels que la concentration superficielle en substrat et la quantité de surface disponible par unité de volume, alors que la concentration volumique en substrat et les paramètres cinétiques de même grandeur comme la constante de Michaelis $\left(K_{m}\right) n^{\prime}$ ont plus de sens lorsque le substrat est insoluble. Cette observation révéla également toute la difficulté à étudier de tels systèmes, une concentration superficielle étant beaucoup plus difficile à mesurer et à contrôler que la concentration volumique d'un substrat soluble.

C'est en cherchant à maîtriser ce paramètre que Robert Verger et Gérard De Haas (figure 3) développeront I'utilisation des films monomoléculaires pour étudier les enzymes lipolytiques $[22,23]$ et élaboreront un premier modèle cinétique dans les années 1970 [24]. L'étalement à l'interface eau-air de films lipidiques permit d'étudier la pénétration dans le film de lipases et de phospholipases injectées dans la sous-phase aqueuse en mesurant l'augmentation de la pression de surface, mais également la lipolyse intervenant à l'interface eau-air. Pour cela, ils inventèrent en particulier la cuve « d'ordre zéro » et le «barostat » permettant de réaliser des expériences de lipolyse à pression de surface et à concentration superficielle en substrat constantes (figure 4), la pression de surface étant utilisée comme paramètre «a minima » pour contrôler la «qualité » de I'interface. Le modèle cinétique Verger-De Haas est la plus simple adaptation du modèle de Michaelis-Menten-Henri à l'hydrolyse interfaciale de lipides à chaînes acyles moyennes, insolubles dans l'eau mais dont les produits sont solubles. La première étape décrit la fixation à l'interface lipide-eau d'une enzyme $(E)$ soluble dans l'eau, via un mécanisme 


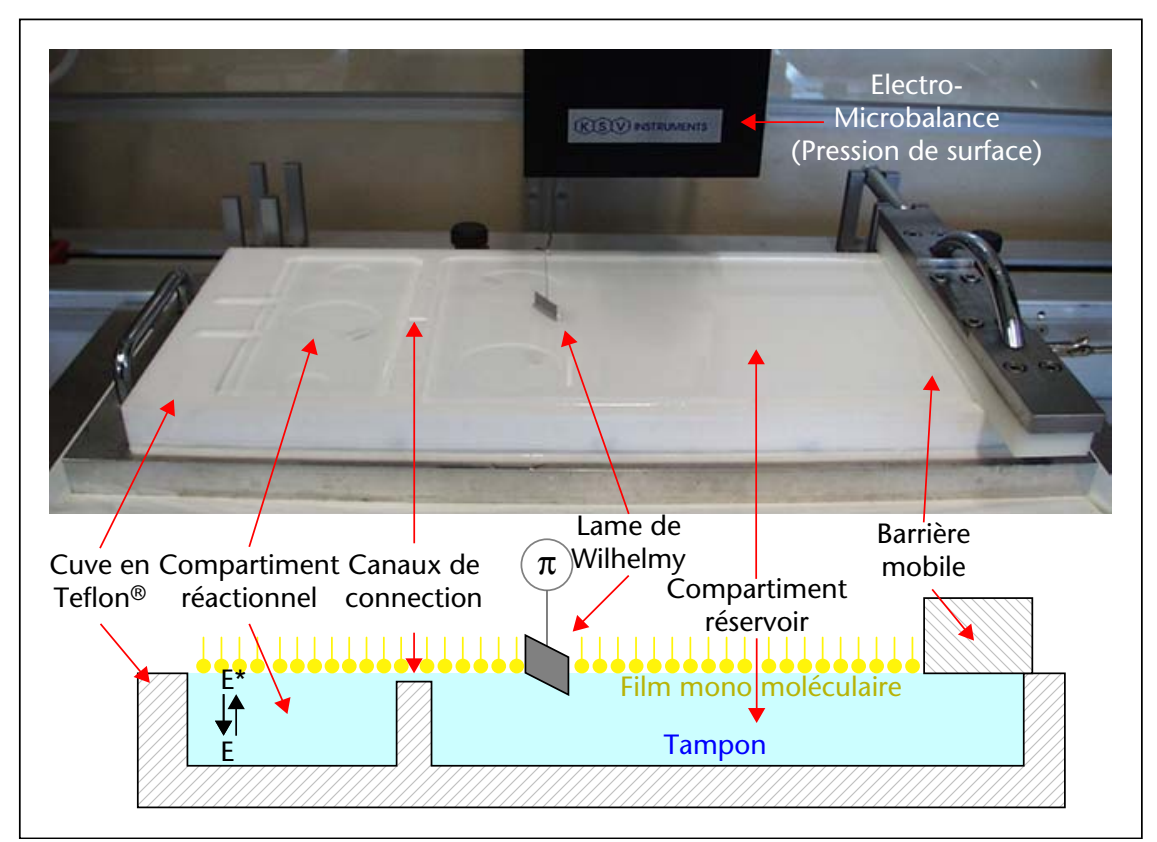

Figure 4. Cuve d'ordre zéro et Barostat. L'injection d'une solution chloroformique de lipides à la surface de cette cuve de Langmuir à deux compartiments permet de former un film monomoléculaire de lipides s'étalant sur toute la surface de la cuve grâce des canaux de surfaces. La diffusion de composés présents dans la phase aqueuse du compartiment réactionnel vers le compartiment réservoir est par contre négligeable. Lorsqu'on injecte une lipase dans le compartiment réactionnel, elle peut se partager entre la phase aqueuse et le film monomoléculaire et hydrolyser les molécules de lipides substrats (par exemple la dicaprine) présent dans le film. Les produits de la réaction, monocaprine et acide caprique, étant solubles dans l'eau, ils sont évacués de l'interface, ce qui induit une diminution de la pression de surface. Cette dernière est mesurée grâce à une lame de platine et une microbalance couplée à un système de régulation. Une barrière mobile en Teflon ${ }^{\circledR}$ présente à la surface de la cuve est alors actionnée pour comprimer le film monomoléculaire et restaurer la pression de surface de consigne. On peut ainsi travailler à pression de surface constante (ou mode " barostat »). II résulte de ce dispositif expérimental que la concentration superficielle en substrat dans le compartiment réactionnel demeure constante pendant la réaction enzymatique, d'où le nom de cuve "d'ordre zéro ». La vitesse d'hydrolyse du substrat est, elle, déterminée par la mesure en fonction du temps de la surface parcourue par la barrière mobile divisée par l'aire moléculaire connue des molécules de substrat.

d'adsorption-désorption réversible (figure 5). Cette étape conduit l'enzyme à un état énergétique plus favorable $\left(E^{*}\right)$ et elle est suivie par une réaction de Michaelis-Menten dans un espace à deux dimensions. L'enzyme présent à I'interface interagit avec une molécule de substrat $(S)$ pour former un complexe enzymesubstrat interfacial $\left(E . S^{*}\right)$, lequel se décompose ensuite pour libérer des produits $\left(P^{*}\right)$ qui vont se solubiliser dans la phase aqueuse. L'utilisation de glycérides à chaînes moyennes comme substrats (trioctanoïne, dicaprine, dilauroyl phosphatidylcholine) a permis d'associer la technique des films monomoléculaires et ce modèle cinétique dans des conditions aussi simples que possibles, alors que l'utilisation de lipides naturels aux chaînes acyles longues aurait conduit à une accumulation de produits à l'interface et à l'absence de contrôle de cette interface. En utilisant cette approche expérimentale simple, de nombreuses études cinétiques des phospholipases A2 et des lipases de diverses origines ont été réalisées. Ces expériences ont notamment montré que les enzymes lipolytiques pouvaient être utilisés comme
« sondes » pour étudier la structure des membranes et déterminer quels paramètres physico-chimiques pouvaient les rendre susceptibles à l'action de ces enzymes [25]. Une application fut par exemple la mise évidence d'une corrélation entre le pouvoir hémolytique de certaines phospholipases A2 et leur capacité à pénétrer dans un film de phospholipide à de hautes pressions de surface mimant celles des membranes biologiques. Cette technique permit également de démontrer sans ambiguité le rôle de la colipase dans l'ancrage de la lipase pancréatique aux interfaces lorsque la pression de surface augmente et que la pénétration de I'enzyme seul devient difficile [26]. La technique des films monomoléculaires et le modèle cinétique de base ont été par la suite régulièrement adaptés pour pouvoir étudier l'inhibition des enzymes lipolytiques [27] ou utiliser des lipides à longues chaînes grâce à des accepteurs de produits de lipolyse comme la $\beta$-cyclodextrine [28].

\section{Purification de la lipase pancréatique de porc et de la colipase}

Bien que diverse préparations de lipase pancréatique de porc aient été disponibles depuis longtemps, il fallut attendre les travaux de thèse de Robert Verger vers la fin des années 1960 pour obtenir une préparation de lipase hautement purifiée. La principale difficulté était alors de séparer la lipase des lipides présents dans les extraits pancréatiques, le pancréas étant un organe naturellement très gras. Pendant plusieurs années fut obtenue une lipase dite "rapide", nommée ainsi car elle était éluée très rapidement des colonnes de filtration sur gel avec une masse moléculaire estimée très largement supérieure à sa masse réelle (50 kDa). II s'agissait en fait d'agrégats lipidiques formés de façon artefactuelle lors du broyage du tissu pancréatique et contenant la lipase pancréatique, son cofacteur la colipase, la phospholipase A2 pancréatique et la cholestérol estérase, toutes ces protéines ayant une affinité pour les lipides [29]. Robert Verger introduisit une étape de délipidation précoce

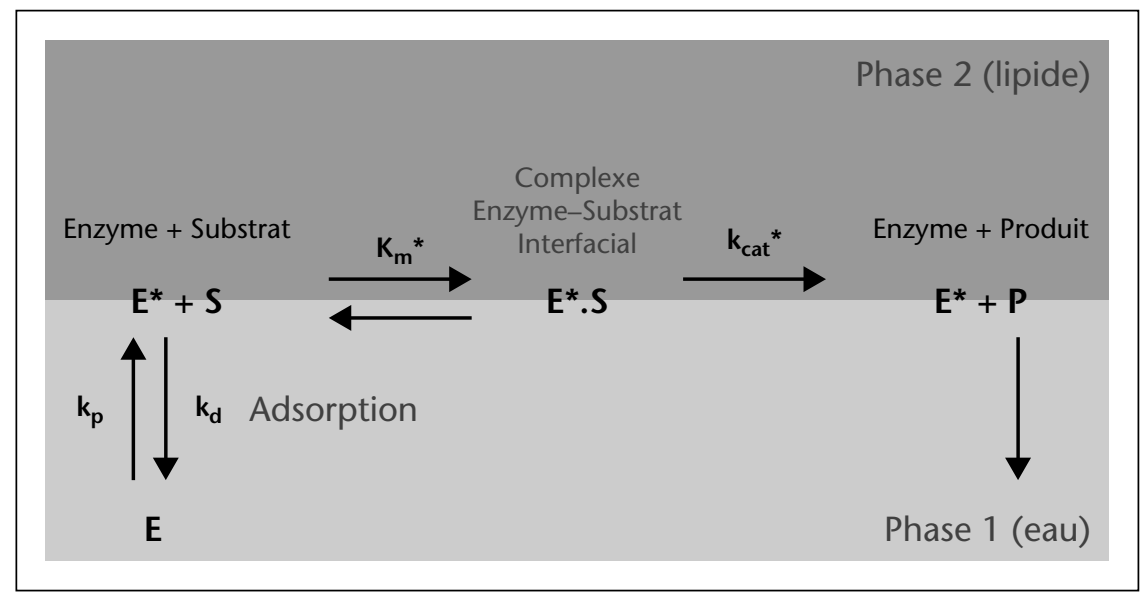

Figure 5. Modèle cinétique interfacial de Verger-De Haas. 
du tissu pancréatique utilisant des solvants organiques. La poudre délipidée ainsi obtenue fut ensuite utilisée pour purifier la lipase par chromatographie [30]. Un procédé analogue de délipidation est utilisé aujourd'hui pour produire les extraits pancréatiques de porc destinés au traitement de l'insuffisance pancréatique. L'interaction lipase-lipides endogènes lors de la production et de la purification des enzymes lipolytiques est en fait un problème d'ordre général que l'on retrouve par exemple aujourd'hui lors de la production de lipases microbiennes [31, 32]. Ces interactions peuvent modifier de façon non négligeable le comportement cinétique des enzymes étudiés et conduire à des artefacts. On peut cependant les utiliser volontairement (Molecular BioImprinting) pour induire des changements conformationnels et moduler l'activité enzymatique des lipases [33, 34].

L'obtention d'une lipase pancréatique de plus grande pureté eut pour conséquence indirecte l'identification de son cofacteur spécifique, la colipase, une petite proteine de $10 \mathrm{kDa}$ ne possédant pas d'activité enzymatique intrinsèque et sécrétée par le pancréas exocrine comme la lipase. Même si l'existence d'une colipase fut proposée dès 1910 [35], c'est en 1971 que cette protéine sera purifiée simultanément à Marseille dans le laboratoire de Pierre Desnuelle [36] et à Lund dans celui du Professeur Bengt Borgström [37]. En présence de sels biliaires, l'activité catalytique de la lipase pancréatique est très fortement réduite car elle ne peut plus s'adsorber à l'interface huile-eau [38]. La colipase est alors requise pour " ancrer » le complexe lipase-colipase à l'interface huile-eau et restaurer son activité. C'est ainsi que fonctionne la lipase pancréatique in vivo. Ce système très spécifique est pourtant passé inaperçu pendant plusieurs années car la lipase pancréatique obtenue sous forme de lipase « rapide » était soit contaminée par de la colipase, soit étudiée dans des conditions ne nécessitant pas ce cofacteur.

\section{Première séquence en acides aminés d'une lipase}

Après l'obtention des premières séquences en acides aminés de la phospholipase A2 pancréatique [39] et de la colipase de porc [40], l'école marseillaise s'illustrera en 1981 par I'obtention de la première structure primaire d'une lipase, celle de la lipase pancréatique de porc [41]. Cette séquence en acides aminés sera obtenue par l'équipe de Mireille Rovery (figure 3) après plusieurs années d'un travail de bénédictin pour produire par protéolyse limitée et séquencer des peptides issus de la lipase pancréatique. L'obtention d'une séquence de 449 acides aminés constituait un exploit avant que les outils de la biologie moléculaire permettant d'obtenir la séquence d'une protéine à partir de celle de son gène soient disponibles puis largement répandus à partir des années 1980.

\section{Le projet européen BRIDGE-T lipase et les premières structures 3D du complexe lipase pancréatique-colipase}

L'année 1990 fut un tournant dans la recherche sur les lipases avec l'obtention des deux premières structures cristallographiques, celles de la lipase pancréatique humaine [42] et de la lipase fongique de Rhizomucor miehei [43]. Ces résultats furent publiés simultanément dans la revue Nature par deux laboratoires industriels. Chez Hoffmann-La Roche à Bâle, Fritz Winkler s'intéressait à la structure de la lipase pancréatique en relation avec le développement de I'inhibiteur de lipase Orlistat ${ }^{\circledR}$ pour le traitement de l'obésité. Chez Novo Nordisk au Danemark, l'équipe de Lars Thim s'intéressait à la lipase de Rhizomucor miehei (Lipozyme ${ }^{\mathrm{TM}}$ ) pour diverses applications industrielles et sa structure fut obtenue en collaboration avec le laboratoire de cristallographie de Guy Dodson à l'université de York. Ces résultats illustrèrent l'intérêt croissant de l'industrie pour les lipases et leurs applications à partir de la fin des années 1980. Le premier producteur mondial d'enzymes industrielles, Novo Nordisk, introduisit en particulier la première lipase recombinante (Lipolase ${ }^{\circledR}$ ) sur le marché des détergents en
1988. Au même moment fut lancé le projet européen BRIDGE-T lipase (1990-1994) dont le but était l'obtention d'une quinzaine de structures de lipases d'intérêt industriel pour mieux comprendre le mode d'action de ces enzymes. Ce projet réunissant 25 laboratoires académiques et industriels (Novo Nordisk, GistBrocades, Unilever et Plant Genetic System) visait également à stimuler un domaine d'activité dans lequel l'Europe était leader avec environ $80 \%$ de la production mondiale d'enzymes industriels. La coordination du projet BRIDGE-T Lipase fut confiée à Robert Verger qui joua un rôle essentiel dans sa préparation grâce aux collaborations qu'il avait nouées avec plusieurs laboratoires européens, en particulier celui du Professeur Gérard De Haas à Utrecht. Grâce à lui, notre laboratoire marseillais joua un rôle important dans le projet BRIDGE-T Lipase avec la caractérisation cinétique des lipases produites dans les différents laboratoires partenaires. II stimula également le développement de la cristallographie à Marseille en apportant au jeune laboratoire de Christian Cambillau (figure 6) ses premiers projets couronnés de succès : la structure de la cutinase de Fusarium solani pisi obtenue par Chrislaine Martinez [44], une première structure du complexe lipase pancréatique humaine-colipase obtenue par Herman van Tilbeurgh [45], puis une seconde structure du même complexe obtenue en présence de phospholipides et de sels biliaires, dans laquelle la lipase pancréatique fut observée pour la première fois dans sa conformation

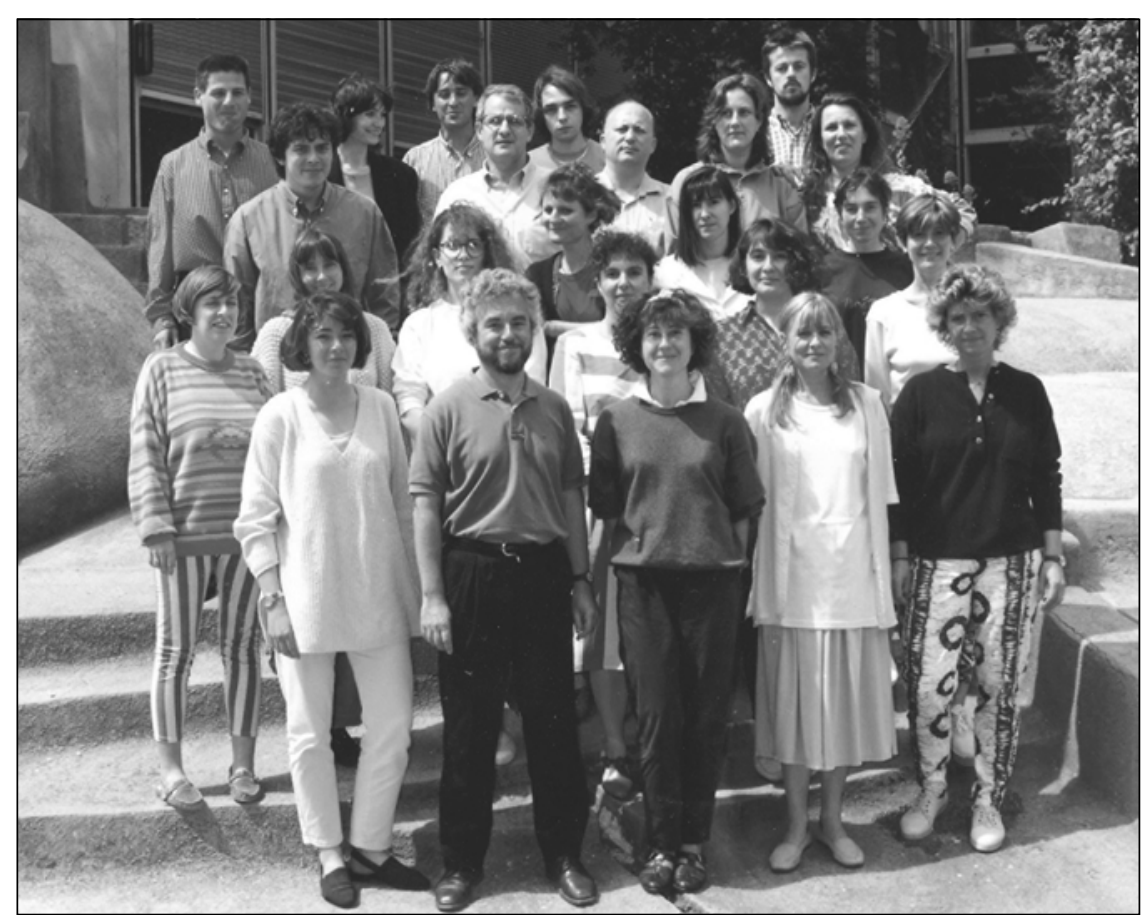

Figure 6. Christian Cambillau et son équipe en 1994. 
« ouverte» et fonctionnelle [46]. Ces trois résultats importants furent publiés dans la revue Nature et ils marquèrent le début d'une production scientifique remarquable dans le domaine de la cristallographie. Le laboratoire marseillais Architecture et fonction des macromolécules biologiques est aujourd'hui l'un des meilleurs laboratoires de cristallographie au niveau mondial.

Cette association locale avec des cristallographes permit aux biochimistes marseillais de rester à la pointe de la recherche sur les lipases alors que la première structure de la lipase pancréatique, obtenue par les chercheurs d'Hoffmann-La Roche, leur avait échappé. Les structures obtenues par Herman van Tilbeurgh (figure 3) apportèrent des informations essentielles sur les relations structure-fonction du complexe lipase-colipase (figure 7).

\section{La lipase gastrique}

Dans les années 1980, l'équipe de Robert Verger s'intéressa également à une autre lipase importante pour la digestion des lipides alimentaires, la lipase préduodénale. L'origine linguale de cette lipase chez l'homme a été postulée pendant de nombreuses années, principalement par le groupe de Margit Hamosh (Georgetown University, USA). L'existence de cette lipase linguale ne reposait en fait que sur de faibles arguments expérimentaux [47] et sur l'extrapolation de résultats obtenus chez le rat, où la lipase préduodénale, la première à avoir été purifiée et caractérisée, est exclusivement linguale [48-50]. Dans notre laboratoire, nous n'avons jamais pu mettre en évidence, chez l'homme, une activité lipolytique significative dans la salive ou à partir de biopsies prélevées dans la partie postérieure de la langue, au niveau des glandes de von Ebner où la lipase aurait dû être localisée. Lors du clonage de la lipase préduodénale humaine en collaboration avec la société CellTech (UK) [51], les essais pour détecter l'ARN messager codant pour cette lipase au niveau lingual se sont avérés infructueux. Cet ARN messager n'a pu être trouvé qu'au niveau de l'estomac. C'est Hervé Moreau qui réalisa un prélèvement systématique de biopsies tout au long du tractus digestif humain à partir de dons d'organes et démontra que l'activité lipolytique correspondant à la lipase préduodénale était localisée exclusivement au niveau de la muqueuse fundique de l'estomac [52]. Par une étude d'immunocytolocalisation, il montra ensuite que la lipase gastrique était présente dans les cellules principales des glandes fundiques, colocalisée avec le pepsinogène [53].

Au-delà des difficultés à reconnaître l'origine de la lipase préduodénale, il était aussi considéré que celle-ci était spécifique des acides gras à

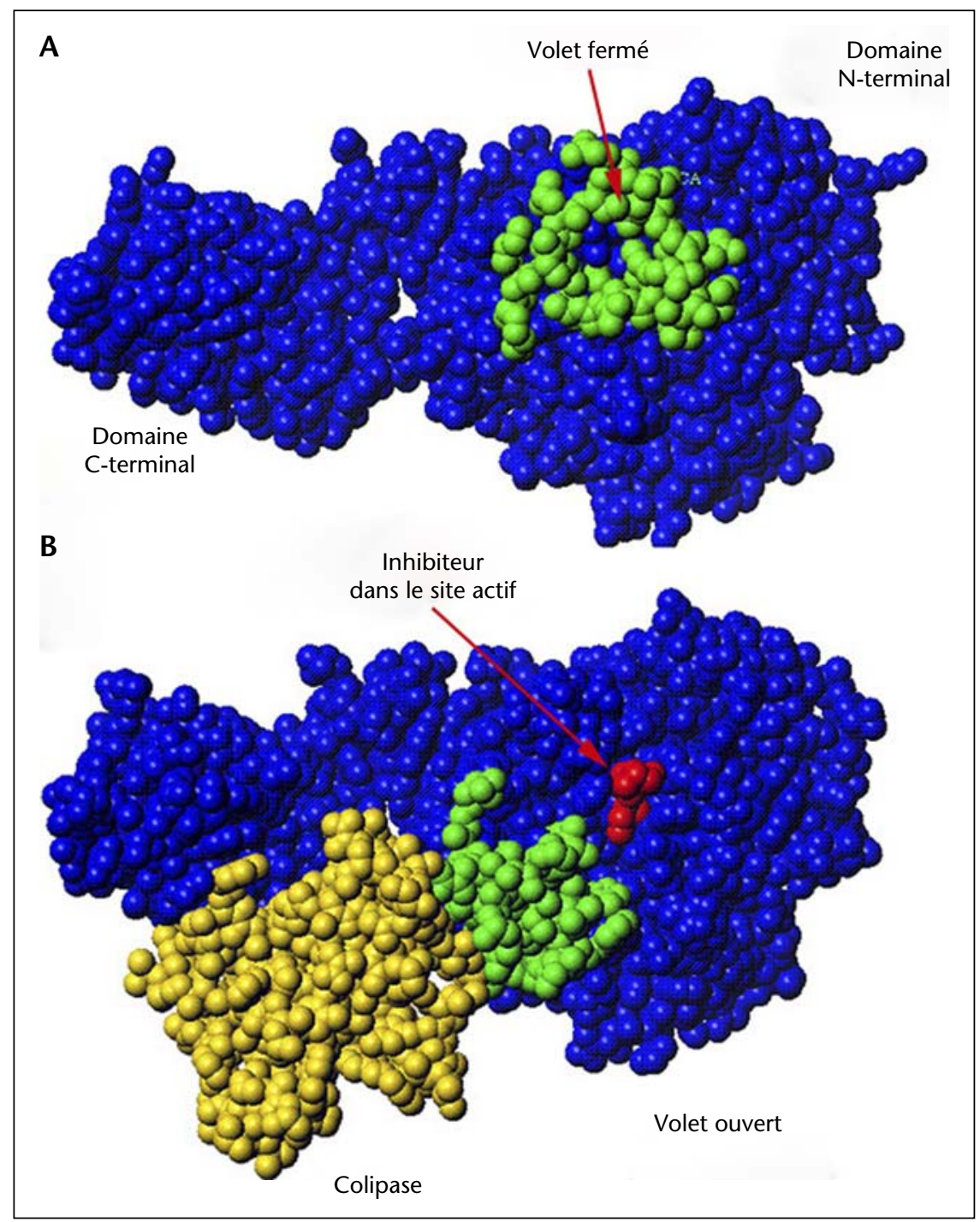

Figure 7. Structure 3D du complexe lipase pancréatique-colipase. A) Lipase pancréatique humaine seule avec le volet contrôlant l'accès au site actif dans sa conformation fermée. B) Complexe lipase pancréatique humaineprocolipase de porc, avec le volet dans sa conformation ouverte et un inhibiteur (C11 alkylphosphonate) lié de façon covalente à la sérine du site actif. La colipase interagit avec le domaine C-terminal de la lipase et avec le volet dans sa conformation ouverte [45, 46, 94]. Le domaine C-terminal de la HPL (structure $\beta$-sandwich) possède une homologie structurale avec les domaines C2 (ou calcium-dependent lipid binding domain) que l'on retrouve dans un grand nombre de protéines interagissant avec les lipides et impliquées dans la signalisation cellulaire. Ce domaine possède une boucle hydrophobe, la boucle $\beta 5$ ', qui joue un rôle important dans l'adsorption de la lipase à l'interface huile-eau [95-97].

chaînes courtes et moyennes [54] et que, par conséquent, son rôle physiologique ne devait être important que chez le nouveau-né pour la digestion des triglycérides du lait [47]. Youssef Gargouri et Robert Verger montrèrent définitivement en 1986 que la lipase gastrique humaine pouvait hydrolyser de façon comparable les triglycérides à chaînes courtes et ceux à chaînes longues [55]. Ewa Rogalska montra par la suite que la spécificité apparente de la lipase gastrique pour les acides gras à chaînes courtes résulte en fait de la stéréosélectivité de cette enzyme pour la position $s n-3$ des triglycérides où les acides gras à chaînes courtes et moyen- nes du lait sont localisés préférentiellement [56].

II restait à déterminer la contribution de la lipase gastrique à la lipolyse des triglycérides alimentaires chez l'homme. J'ai obtenu en 1988 un contrat CIFRE avec les Laboratoires Jouveinal pour préparer ma thèse sur ce sujet dans le laboratoire de Robert Verger. On souhaitait déjà à cette époque utiliser la lipase gastrique, stable et active en milieu acide, pour améliorer la digestion des graisses chez les insuffisants pancréatiques. Le rôle physiologique exact de la lipase gastrique chez le sujet sain était cependant inconnu et l'on ne dispo- 


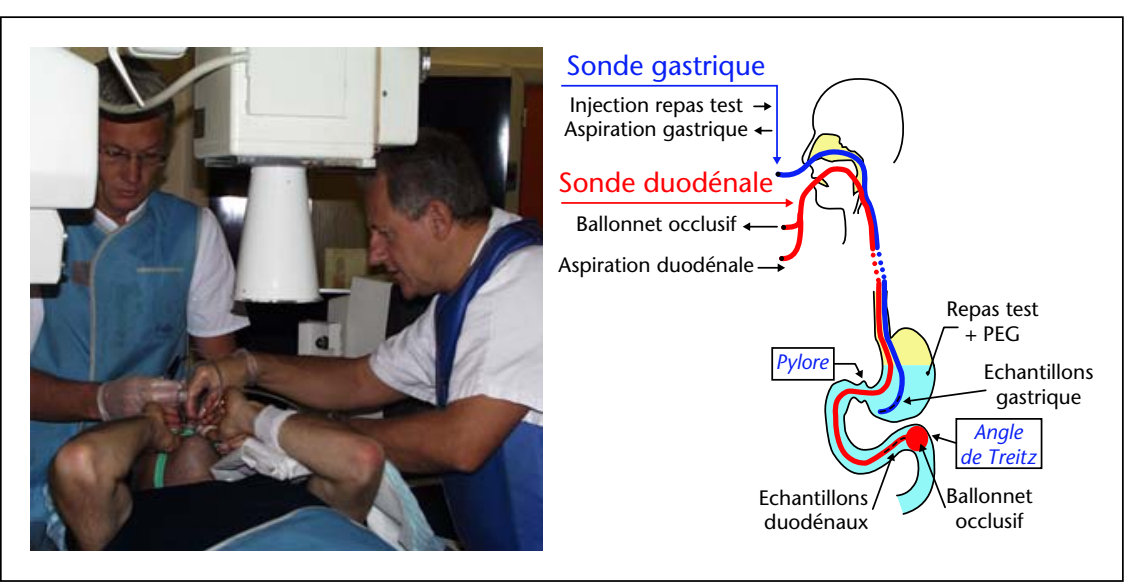

Figure 8. Etude clinique de la lipolyse gastro-intestinale. Mise en place de sondes gastrique et duodénale par le Professeur René Laugier et le Dr Christophe Renou à l'Hôpital de la Timone à Marseille. Dispositif expérimental pour prélever des échantillons gastriques et intestinaux au cours de la digestion d'un repas test.

sait pas de données quantitatives sur les sécrétions des lipases digestives en général et sur les niveaux de lipolyse respectifs dans l'estomac et I'intestin grêle. Seuls des débits ou concentrations estimés en unités enzymatiques étaient disponibles dans la littérature pour la lipase pancréatique mais la disparité des résultats obtenus dans divers laboratoires était très grande. Nous nous sommes alors associés à d'autres spécialistes marseillais, ceux du pancréas issus de l'école du Professeur Henri Sarles, pour réaliser des études in vivo, tout d'abord chez le chien [57, 58], puis chez l'homme [59]. Grâce au Professeur René Laugier à l'Hôpital St Marguerite à Marseille, nous avons pu associer les techniques d'investigation des fonctions digestives in vivo (figure 8) aux tests enzymatiques spécifiques permettant de discriminer les activités des lipases gastrique et pancréatique et à l'analyse quantitative des produits de lipolyse présents dans les échantillons recueillis dans l'estomac et l'intestin grêle. Nous avons pu ainsi établir les contributions respectives des lipases gastrique et pancréatique à la lipolyse gastro-intestinale d'un repas test. La lipase gastrique permet la libération d'une chaîne acyle sur les quatre qui sont libérées lors de la conversion de 2 molécules de triglycérides en acides gras et 2 molécules de monoglycérides, les produits de lipolyse absorbés au niveau intestinal [59]. Grâce à ces travaux et aux nombreuses études cliniques qui ont suivies, nous savons que la sécrétion de la lipase pancréatique humaine (80 à $400 \mathrm{mg}$ par repas) est pondéralement bien plus importante que celle de la lipase gastrique (10 à $25 \mathrm{mg}$ par repas) chez le sujet sain. La lipolyse dans l'estomac due à la seule lipase gastrique est cependant significative: de $10 \%$ avec un repas mixte solide-liquide jusqu'à $25 \%$ avec un repas test liquide contenant des triglycérides finement émulsifiés $[60,61]$.
Plus récemment, nous avons montré que la sécrétion de la lipase gastrique est augmentée de 3-4 fois chez l'insuffisant pancréatique sévère ne sécrétant pratiquement plus de lipase pancréatique. Cette compensation n'est que partielle mais elle permet la digestion d'environ $30 \%$ des triglycérides ingérés, ce qui démontre une fois de plus que la contribution de la lipase gastrique n'est pas négligeable [62].

Parallèlement à ces études physiologiques, la caractérisation structurale de la lipase gastrique s'est poursuivie avec l'obtention des structures 3D des lipases gastriques humaine et canine $[63,64]$. Ces structures ont montré l'existence d'un volet contrôlant l'accès au site actif comme dans la lipase pancréatique (figure 9).

\section{Applications médicales des lipases et de leurs inhibiteurs}

Cette association unique entre des biochimistes et des médecins gastroentérologues a été très rapidement reconnue par l'industrie pharmaceutique (contrats avec les sociétés Roche, Solvay Pharmaceuticals, Sanofi-Aventis, Novo Nordisk, Meristem Therapeutics, Laboratoires Jouveinal, Takeda, Mayoly Spindler). Elle a permis de développer des outils d'investigation de la lipolyse in vivo et d'appliquer ces outils à l'étude d'inhibiteurs de lipases pour le traitement de l'obésité et à l'enzymothérapie de substitution pour le traitement de l'insuffisance pancréatique.

Nous avons contribué en particulier à l'étude de la tétrahydrolipstatine (THL ou Orlistat ${ }^{\circledR}$ ), le seul inhibiteur de lipase aujourd'hui disponible sur le marché $\left(\right.$ Xenical $\left.^{\circledR}\right)$. En inhibant les lipases digestives humaines (HGL et HPL), on peut diminuer l'absorption intestinale des produits de lipolyse des graisses alimentaires, et donc l'apport calorique. Les propriétés physicochimiques et inhibitrices de l'Orlistat ${ }^{\circledR}$ (figure 10) ont été largement étudiées à Marseille [65-72]. Nous avons également réalisé la première étude clinique permettant de décrire quantitativement l'inhibition in vivo des lipases gastrique et pancréatique par l'Orlistat ${ }^{\circledR}$ au cours de repas tests chez des volontaires sains [73]. L'Orlistat ${ }^{\circledR}$ est aujourd'hui le premier médicament anti-obésité avec un marché annuel de 350 millions de dollars US.

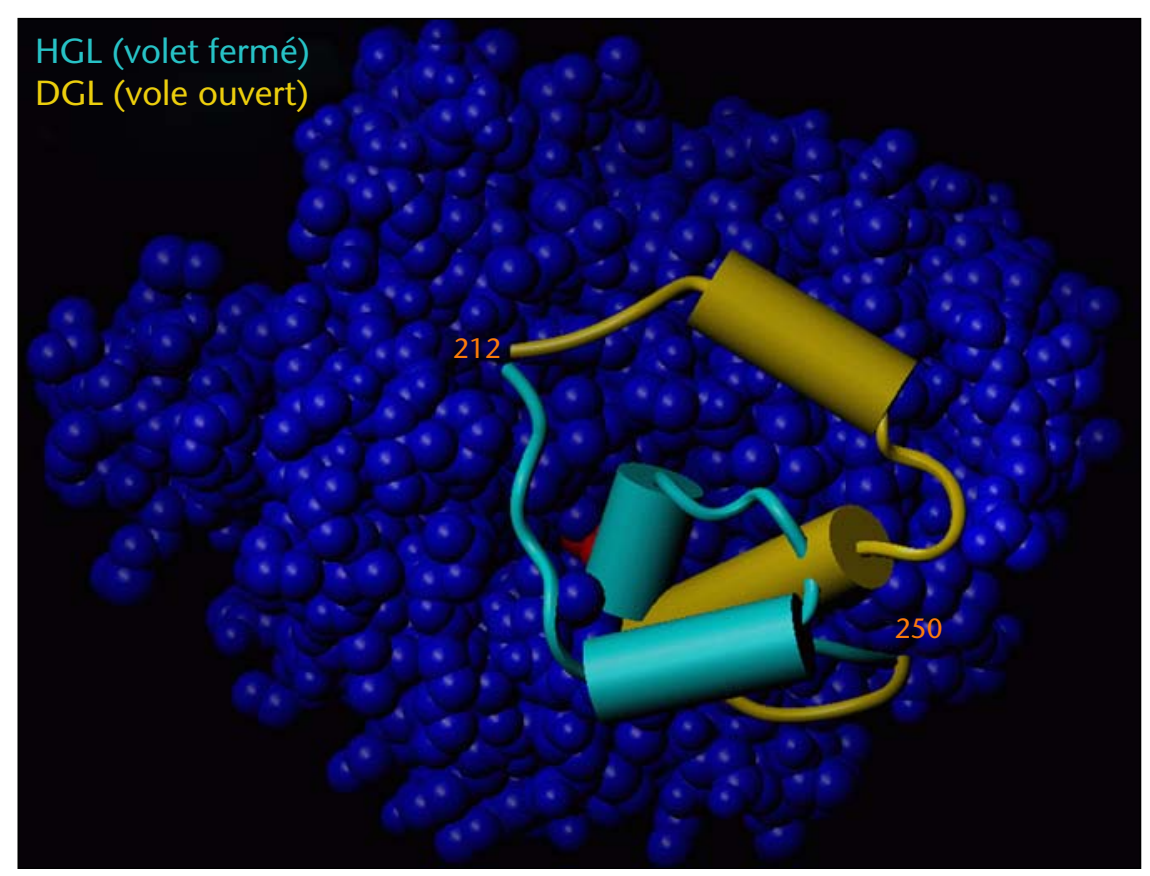

Figure 9. Structures 3D superposées de la lipase gastrique humaine (HCL) et de la lipase gastrique de chien (DGL). 
L'inhibition de la lipase hormono-sensible (HSL), qui est également une nouvelle approche thérapeutique potentielle, mais cette fois dans le domaine du diabète de type II non insulino-dépendant. En diminuant l'activité de la HSL par des inhibiteurs spécifiques, il est possible de réduire le taux d'acides gras libres circulant et agir alors indirectement sur le métabolisme du glucose. Des inhibiteurs spécifiques de la famille de la HSL ont été synthétisés par Aventis et étudiées dans notre laboratoire $[74,75]$.

Le domaine de l'enzymothérapie de substitution vise au contraire à restaurer une activité lipolytique dans le tractus digestif pour le traitement de l'insuffisance pancréatique, particu- lièrement sévère chez des patients atteints de pancréatite chronique et de mucoviscidose. Les premières études réalisées chez le chien pour déterminer la contribution de la lipase gastrique $[57,58]$ nous avaient permis de purifier et de caractériser la DGL native. II s'est avéré que cette enzyme était, de toutes les lipases connues, la plus active à pH acide sur les triglycérides naturels [76] et elle semblait donc bien adaptée à une action dans les conditions acides du tractus digestif des insuffisants pancréatiques [77]. Le projet de produire une lipase gastrique de chien recombinante (rDGL) est né de ces études et la société Meristem Therapeutics a utilisé son savoir-faire dans le domaine des plantes transgénique pour introduire son

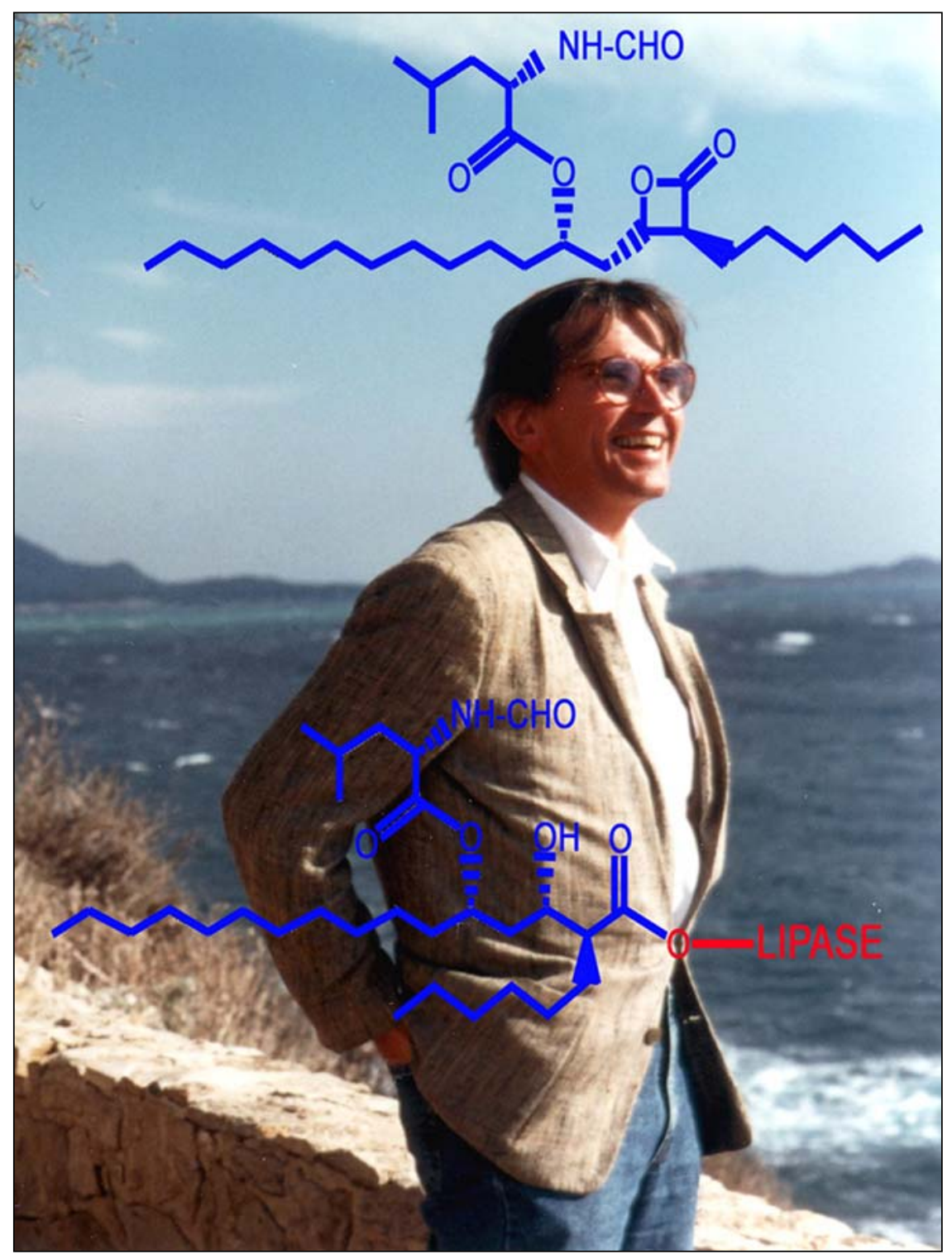

Figure 10. Hans Lengsfeld à Marseille en 1994. Il est le découvreur de la lipstatin [98], le précurseur naturel de la tétrahydrolipstatine ou Orlistat ${ }^{\circledR}$. Les molécules insérées dans la photographie montrent comment un intermédiaire réactionnel covalent stable est formé lors de l'attaque nucléophile de la sérine catalytique de la lipase sur la fonction $\beta$-lactone cyclique de l'Orlistat ${ }^{\circledR}$. gène dans le maïs [78]. En 2003, la rDGL produite dans le maïs transgénique a obtenu le statut de médicament orphelin de l'Agence européenne du médicament (EMEA) pour le traitement de la mucoviscidose.

\section{La recherche actuelle sur les lipases à Marseille}

L'étude des enzymes lipolytiques a permis le développement d'une enzymologie « interfaciale » qui, loin d'être une curiosité, concerne de très nombreux enzymes à l'intérieur comme à l'extérieur de la cellule vivante. À Marseille, nous poursuivons le développement de techniques expérimentales et de modèles cinétiques pour étudier l'adsorption de ces enzymes sur leur substrat insoluble, les changements conformationnels associés à cette adsorption ou la précédant, et les facteurs influençant la stabilité et l'activité des enzymes aux interfaces. L'utilisation de la technique des films monomoléculaires reste d'actualité mais nous utilisons également diverses techniques spectroscopiques qui viennent compléter les données structurales obtenues par diffraction des rayons $X$. Parmi les résultats marquants obtenus ces dernières années, il y a la compréhension de l'activité catalytique optimale de la lipase gastrique à pH acide [79], et l'utilisation du marquage de spin dirigé, couplé à la spectroscopie de résonance paramagnétique électronique (RPE) pour étudier les changements conformationnels de la lipase pancréatique [80].

La lipase gastrique est stable à $\mathrm{pH}$ acide et la rDGL possède une activité optimale à $\mathrm{pH} 4$ sur les triglycérides à chaînes longues [76]. Pendant plusieurs années, nous avons essayé de comprendre cette activité au niveau moléculaire, notamment par l'obtention des structures $3 \mathrm{D}$ des lipases gastriques humaine et canine, respectivement dans leurs conformations ouverte et fermée $[63,64]$. Ces structures ont montré la présence d'une triade catalytique Ser-His-Asp comparable à celle observée dans d'autres lipases agissant de façon optimale à $\mathrm{pH}$ neutre ou plus alcalin, et aucun élément structural n'a permis d'expliquer un éventuel déplacement du pKa apparent de l'histidine vers des valeurs inférieures à 6 . Ces observations structurales ont été confirmées par le fait que la $\mathrm{rDGL}$ pouvait agir sur une solution de butyrate de vinyle avec une activité optimale à $\mathrm{pH}$ 7. Dans certaines conditions (substrat et enzyme soluble), la lipase gastrique peut donc hydrolyser les liaisons esters comme d'autres hydrolases à serine classiques. Le butyrate de vinyle étant partiellement soluble dans l'eau, nous avons également réalisé des expériences $d^{\prime}$ 'hydrolyse par la rDGL au-delà de sa limite de solubilité. Un déplacement de l'activité optimale vers les $\mathrm{pH}$ acides a alors été observé, 
suggérant que l'interaction de la lipase avec un substrat insoluble était elle aussi dépendante du $\mathrm{pH}$. Des expériences réalisées avec une émulsion de triglycérides à longues chaînes ont alors montré que la rDGL se fixe préférentiellement à l'interface huile-eau à $\mathrm{pH}$ acide. Pour étudier l'effet du pH sur l'étape d'adsorption de la rDGL à l'interface indépendamment de I'hydrolyse du substrat, nous avons utilisé des surfaces solides hydrophobes comme interfaces modèles et nous avons mesuré l'adsorption de la rDGL par spectroscopie de fluorescence de surface (total internal reflection fluorescence : TIRF) ou à l'aide d'une microbalance à quartz (QCM). Les deux approches ont montré une adsorption réversible et $\mathrm{pH}$-dépendante de la $\mathrm{rDGL}$ en présence de sels biliaires, avec un optimum à $\mathrm{pH} 5\left(K_{d}=6,5 \mathrm{nM}\right)$. Ces résultats ont suggéré que l'activité optimale de la lipase gastrique à $\mathrm{pH}$ acide était seulement « apparente » et résultait du fait que l'étape d'adsorption $\mathrm{pH}$-dépendante de la lipase à l'interface huile-eau est l'étape limitante dans le processus global d'hydrolyse d'un substrat insoluble [79]. Cette particularité cinétique associée à l'action d'un enzyme soluble sur un substrat insoluble devra désormais être prise en considération lorsqu'il s'agira d'étudier l'effet du pH sur d'autres enzymes agissant aux interfaces.

La spectroscopie RPE a été utilisée pour étudier les changements conformationnels de la lipase pancréatique humaine (HPL) [80]. Les conformations fermées (site actif inaccessible) et ouverte (site actif accessible) du volet de la HPL ont été associées à l'état initial et à l'état final du processus d'activation de la lipase (supposé se produire à l'interface), mais aucune relation directe entre ces observations structurales et le comportement cinétique de la HPL n'a pu être établie jusqu'à présent. De plus, plusieurs études ont suggéré que la lipase pouvait être déjà « activée » (ouverture du volet) en solution en présence de détergents et de colipase [81, 82]. Les données structurales sur les différentes conformations du volet ayant été obtenues avec des lipases cristallisées, il n'était en fait pas évident d'associer ces données structurales avec des données cinétiques obtenues en phase liquide. La spectroscopie RPE nous a permis d'étudier le changement conformationnel du volet de la HPL en solution et les contributions respectives des partenaires physiologiques de la lipase que sont la colipase et les sels biliaires. Une sonde paramagnétique (MTSL) a été introduite au niveau du volet grâce à la mutation D249C permettant le greffage covalent de la sonde et de la cystéine libre. Deux composants distincts du spectre RPE de la sonde ont pu être identifiés et attribués sans ambiguité aux conformations fermée (mouvement rapide du radical) et ouverte (mouvement lent du radical) du volet de la HPL, notamment grâce à des expériences réalisées avec l'inhibiteur E600. Nous avons montré que la conformation ouverte du volet peut être induite en solution en présence d'une concentration supramicellaire en sels biliaires, et que ce phénomène est réversible. La colipase seule n'induit pas l'ouverture du volet, mais en présence de sels biliaires, elle permet d'obtenir une proportion de forme ouverte plus importante qu'en présence des sels biliaires seulement. Nous poursuivons actuellement ces études en introduisant d'autres facteurs dans le système expérimental : présence de lipides, variation du $\mathrm{pH} .$. Grâce à cette technique, nous avons aujourd'hui des informations structurales sur l'activation de la lipase obtenues dans des conditions proches de celles mises en œuvre lors des études cinétiques de cet enzyme. Nous espérons établir des relations structurefonction plus précises de la lipase pancréatique et des lipases en général.

Parallèlement à ces travaux sur la lipase pancréatique dite " classique ", nous nous intéressons depuis plusieurs années à de nouvelles protéines apparentées à la lipase pancréatique, les PLRP (pancreatic lipase-related proteins). Trois gènes distincts codant pour des lipases pancréatiques ou protéines apparentées sont en fait exprimés dans le pancréas exocrine humain. L'un de ces gènes code pour la lipase pancréatique classique (HPL), qui possède une activité très sélective vis-à-vis des triglycérides et joue un rôle prépondérant dans la digestion des lipides alimentaires. Nous avons montré la présence des deux autres protéines (HPLRP1 et HPLRP2) dans la sécrétion pancréatique exocrine $[83,84]$. Jusqu'à présent, aucune activité enzymatique n'a pu être décelée chez la HPLRP1 ainsi que chez les PLRP1 de diverses espèces et leur rôle physiologique est encore inconnu. Nous avons obtenu la structure 3D de la PLRP1 du chien et montré que son absence d'activité était due à un encombrement stérique au niveau du site actif [85].

Les lipases pancréatiques apparentées de type 2 peuvent hydrolyser in vitro les triglycérides, les phospholipides avec une activité phospholipase $A 1$ et les galactolipides $[86,87]$. Nous avons d'abord caractérisé les PLRP2 du cobaye et du ragondin, deux espèces chez qui il n'existe pas de phospholipase A2 pancréatique mais où le pancréas produit la PLRP2 en grande quantité et à des niveaux équivalents à ceux de la lipase pancréatique classique. Chez ces deux espèces, et chez les herbivores en général [88], il semble que les phospholipides et les galactolipides alimentaires soient les substrats physiologiques de la PLRP2. Chez d'autres espèces, la situation est beaucoup plus confuse et il est difficile de proposer un rôle physiologique unique pour les PLRP2. Contrairement à la lipase pancréatique classique, les PLRP2 peuvent être exprimées dans divers tissus ou types cellulaires : entérocytes et cellules acineuses du pancréas chez le rat, lymphocytes $T$ chez la souris, production par la glande bulbo-urétrale et sécrétion dans le plasma séminal chez le bouc. Chez la souris en particulier, la PLRP2 contribue à la cytotoxicité des lymphocytes $T$ et semble donc impliquée dans la réponse immunitaire [89]. La PLRP2 humaine est présente dans la sécrétion du pancréas exocrine où elle est majoritairement responsable de l'activité galactolipase [84]. Son activité lipasique étant inhibée par les sels biliaires et faiblement restaurée par la colipase, et son activité phospholipase A1 étant faible, la PLRP2 humaine ne joue probablement pas un rôle crucial dans la digestion des triglycérides et des phospholipides alimentaires. Son principal rôle physiologique semble donc être I'hydrolyse des galactolipides, les principaux lipides présents dans les légumes et les fruits que nous consommons chaque jour [90]. La découverte chez l'homme d'un enzyme permettant la digestion des galactolipides a remis en cause certaines idées reçues sur la digestion. Les galactolipides étant les principaux lipides membranaires chez les plantes, ce sont aussi les lipides les plus abondants sur la terre. Les galactolipases pourraient se révéler intéressantes pour transformer et valoriser ces lipides.

Un nouvel axe de recherche concerne les lipases microbiennes et l'association de ces enzymes avec des micro-organismes pathogènes. La jeune équipe Lipolyse et pathogénie bactérienne dirigée par Stéphane Canaan étudie les lipases de Mycobacterium tuberculosis par une approche de génomique structurale et fonctionnelle [91, 92]. Les enzymes lipolytiques chez les mycobactéries ont été peu étudiés bien que les lipides représentent 30 à $40 \%$ du poids sec des mycobactéries et que $6 \%$ de leur génome code pour des protéines impliquées dans le métabolisme des lipides. Les enzymes lipolytiques jouent probablement un rôle dans la mobilisation énergétique en permettant I'utilisation des acides gras comme source de carbone, mais également dans la virulence (hydrolyse des phospholipides des cellules hôtes). Ces enzymes sont donc potentiellement des cibles thérapeutiques pour le développement de nouveaux agents antituberculeux. L'expérience acquise à Marseille dans le domaine des inhibiteurs de lipase sera certainement un atout pour relever ce défi, le traitement de la tuberculose étant toujours une priorité internationale avec la recrudescence de la maladie associée à l'épidémie de sida dans le monde.

Enfin, un dernier axe de recherche concerne l'action des enzymes lipolytiques du tractus digestif humain sur les "véhicules lipidiques» (excipients) utilisés dans les formes galéniques 
permettant l'administration par voie orale de certains médicaments hydrophobes (cyclosporine, inhibiteur DMP 323 de la protéase du HIV, $\alpha$-tocophérol, nifédipine, 17- $\beta$ estradiol, ontazolast, propranolol, piroxicam, fénofibrate, ibuprofène). Ces véhicules lipidiques se présentent sous diverses formes (micro-émulsions, micelles, particules solides) et contiennent divers composés amphiphiles (acylglycérols, esters de PEG) pouvant être des substrats pour les lipases [93]. Cette lipolyse a été peu étudiée jusqu'à présent mais elle intéresse de plus en plus l'industrie pharmaceutique car la lipolyse gastro-intestinale et la digestion des lipides alimentaires influencent certainement la biodisponibilité des molécules hydrophobes administrées par voie orale à l'aide d'excipients lipidiques. Jusqu'à présent, seule une approche empirique était utilisée pour concevoir ces formes galéniques. Aujourd'hui, I'industrie pharmaceutique recherche une approche plus rationnelle basée sur des tests préliminaires in vitro et une bonne corrélation in vitro-in vivo. II faut savoir qu'une grande majorité (environ $70 \%$ ) des nouvelles molécules issues de la recherche pharmaceutique sont hydrophobes et nécessitent l'emploi de tels "véhicules" pour être solubilisées ou dispersées. L'administration par voie orale étant une cible prioritaire pour I'industrie pharmaceutique, la galénique des molécules hydrophobes revêt une importance stratégique et conduira certainement à de nombreuses recherches fondamentales dans les années à venir. Les lipases ont encore une place ce choix dans cette recherche future.

\section{RÉFÉRENCES}

1. DESNUelle $P$, NAUdet M. Phénomènes de transestérification entre triglycérides. I. Formation de glycérides partiels à partir de la tristéarine et de la trioléine. Bull Soc Chim 1946; 90.

2. DESNUELLE $P$, NAUDET M, CONSTANTIN M]. Action des sels de calcium sur l'hydrolyse des triglycérides par la pancreatine et le suc pancréatique. Biochim Biophys Acta 1950; 5: 561-8.

3. DESNUELLE $P$, NAUDET M, CONSTANTIN M]. Sur une lipolyse génératrice de glycérol. Biochim Biophys Acta $1951 ; 7$ : 251-6.

4. MATTSON FH, BECK LW. The specificity of pancreatic lipase for the primary hydroxyl groups of glycerides. / Biol Chem 1956; 219 : 735-40.

5. DESNUELLE P, SAVARY P. Specific elements of enzymatic hydrolysis of triglycerides. Biochim Biophys Acta 1956; 21 : 349-60.

6. SAVARY P, FLANZY J, DESNUELLE P. Utilisation de la lipase pancréatique pour l'étude de la structure des corps gras naturels. Biochim Biophys Acta $1957 ; 24: 414-23$.
7. SAVARY $P$, DESNUELLE $P$. Sur la distribution des chaînes saturées et insaturées entre les positions externe et interne des triglycérides mixtes végétaux. Biochim Biophys Acta 1961; 50: 319-24.

8. SAVARY P, CONSTANATIN MI, DESNUELLE P. Sur la structure des triglycérides des chylomicrons lymphatiques chez le rat. Biochim Biophys Acta $1961 ; 48: 562-71$.

9. SAVARY P, FLANZY J, CONSTANTIN M], DESNUELLE $P$. Etude de la lipase du fruit du palmier à huile (Elaeis guineensis). Bull Soc Chim Biol (Paris) 1957 ; 39 : 413-8.

10. SAVARY P, FLANZY ], DESNUELLE P. Hydrolyse des triglycérides par la lipase du Ricin. Bull Soc Chim Biol (Paris) 1958 ; 40 : 637-45.

11. ENTRESSANGLES B, SARI H, DESNUELLE P. On the positional specificity of pancreatic lipase. Biochim Biophys Acta 1966 ; 125 : 597-600.

12. SEMERIVA M, BENZONANA G, DESNUELLE $P$. Sur la lipase de Rhizopus arrhizus. I. Spécificité de position. Bull Soc Chim Biol (Paris) 1967 ; 49 : 71-9.

13. BENZONANA G, ESPOSITO $S$. On the positional and chain specificities of Candida cylindracea lipase. Biochim Biophys Acta 1971; 231 : 15-22.

14. HOLWERDA K, VERKADE PE, DE WILLIGEN AHA. Vergleichende Untersuchungen über die Verseifungsgeschwindigkeit einiger einsäuriger Triglyceride unter Einfluss von Pankreasextrakt. Rec Trav Chim Pays-Bas 1936 ; 55 : 43-57.

15. SCHØNHEYDER F, VOLQVARTZ K. On the affinity of pig pancreas lipase for tricaproin in heterogenous solution. Acta Physiol Scand $1945 ; 9: 57-67$.

16. SCHØNHEYDER F, VOLQVARTZ K. Studies of the lipolytic enzyme reaction. III. Hydrolysis of tripopionyl glycerol. Biochim Biophys Acto $1952 ; 8: 407-15$

17. SCHØNHEYDER F, VOLQVARTZ K. Lipolytic enzyme action. VI. Hydrolysis of trilauroyl glycerol by pancreatic lipase. Biochim Biophys Acto $1954 ; 15$ : 288-90

18. SARDA L, DESNUELLE $P$. Action de la lipase pancréatique sur les esters en émulsion. Biochim Biophys Acta 1958 ; 30 : 513-21.

19. FERRATO F, CARRIERE F, SARDA L, VERGER R. A critical reevaluation of the phenomenon of interfacial activation. Methods Enzymol 1997 ; 286 : 327-47.

20. DESNUELLE $P$, SARDA L, AILHAUD G. Inhibition de la lipase pancréatique par le diéthyl-pnitrophényl phosphate en émulsion. Biochim Biophys Acta $1960 ; 37$ : 570-1.

21. BENZONANA G, DESNUELLE $P$. Etude cinétique de l'action de la lipase pancréatique sur des triglycérides en émulsion. Essai d'une enzymologie en milieu hétérogène. Biochim Biophys Acta $1965 ; 105: 121-36$
22. VERGER R, DE HAAS GH. Enzyme reactions in a membrane model. 1: A new technique to study enzyme reactions in monolayers. Chem Phys Lipids $1973 ; 10$ : 127-36.

23. VERGER R, MIERAS MCE, DE HAAS GH. Action of phospholipase $A$ at interfaces. / Biol Chem $1973 ; 248: 4023-34$.

24. VERGER R, DE HAAS GH. Interfacial enzyme kinetics of lipolysis. Annu Rev Biophys Bioeng $1976 ; 5: 77-117$

25. VERGER R, RIETSCH J, VAN DAM-MIERAS MCE, DE HAAS GH. Comparative studies of lipase and phospholipase A2 acting on substrate monolayers. / Biol Chem 1976 ; 251 : 3128-33.

26. VERGER R, RIETSCH J, DESNUELLE P. Effects of colipase on hydrolysis of monomolecular films by lipase. I Biol Chem $1977 ; 252$ : 4319-25.

27. RANSAC S, RIVIERE C, GANCET C, VERGER R DE HAAS CH. Competitive inhibition of lipolytic enzymes. I. A kinetic model applicable to water-insoluble competitive inhibitors. Biochim Biophys Acta $1990 ; 1043$ : 57-66.

28. PANAIOTOV I, VERGER R. Enzymatic reactions at interfaces. Interfacial and temporal organisation of enzymatic lipolysis. In : Baszkin A, Norde W, eds. Physical Chemistry of Biological Interfaces. New York : Marcel Dekker, 2000 : 359-400.

29. VERGER R. Pancreatic lipases. In : Borgström B, Brockman HL, eds. Lipases. Amsterdam : Elsevier, 1984 : 83-149.

30. VERGER R, DE HAAS GH, SARDA L, DESNUELLE P. Purification from porcine pancreas of two molecular species with lipase activity. Biochim Biophys Acta $1969 ; 188$ : 272-82.

31. ALOULOU A, RODRIGUEZ JA, PUCCINELLID, ET AL. Purification and biochemical characterization of the LIP2 lipase from Yarrowia lipolytica. Biochim Biophys Acta 2007 ; 1771 : 228-37.

32. DIAZ JC, CORDOVA J, BARATTI J, CARRIERE F, ABOUSALHAM A. Effect of nonionic surfactants on Rhizopus homothallicus lipase activity: a comparative kinetic study. Mol Biotechnol 2007 ; 35 : 205-14.

33. MINGARRO I, ABAD C, BRACO L. Interfacial activation-based molecular bioimprinting of lipolytic enzymes. Proc Natl Acad Sci USA 1995 . $92: 3308-12$.

34. GONZALEZ-NAVARRO H, BANO MC, ABAD C. The closed/open model for lipase activation. Addressing intermediate active forms of fungal enzymes by trapping of conformers in waterrestricted environments. Biochemistry 2001 ; $40: 3174-83$

35. ROSENHEIM O. On pancreatic lipase III. The separation of lipase from its co-enzyme. J Physiol $1910 ; 40$ : XIV-XVI.

36. MAYLIÉ MF, CHARLES M, GACHE C, DESNUELLE P. Isolation and partial identification of a pancreatic colipase. Biochim Biophys Acta $1971 ; 229$ : 286-9. 
37. BORGSTRÖM B, ERLANSON C. Pancreatic juice co-lipase : Physiological importance. Biochim Biophys Acta 1971 ; 242 : 509-13.

38. BEZZINE S, FERRATO F, IVANOVA MG, LOPEZ V, VERGER R, CARRIERE F. Human pancreatic lipase : colipase dependence and interfacial binding of lid domain mutants. Biochemistry $1999 ; 38: 5499-510$.

39. MAROUX S, PUIGSERVER A, DLOUHA V, ET AL. Amino acid sequence of phospholipase $A$ from porcine pancreas. Biochim Biophys Acta 1969 ; $188: 351-2$.

40. CHARLES M, ERLANSON C, BIANCHETTA J, JOFFRE J, GUIDONI A, ROVERY M. The primary structure of porcine colipase II. I. The amino acid sequence. Biochim Biophys Acta 1974 359 : 186-97

41. DE CARO J, BOUDOUARD M, BONICEL J, GUIDONI A, DESNUELLE P, ROVERY M. Porcine pancreatic lipase. Completion of the primary structure. Biochim Biophys Acta 1981; 671 : 129-38.

42. WINKLER FK, D'ARCY A, HUNZIKER W. Structure of human pancreatic lipase. Nature 1990 ; $343: 771-4$.

43. BRADY L, BRZOZOWSKI AM, DEREWENDA ZS, ET AL. A serine protease triad forms the catalytic centre of a triacylglycerol lipase. Nature 1990 ; 343 : 767-70.

44. MARTINEZ C, DE GEUS P, LAUWEREYS M, MATTHYSSENS G, CAMBILLAU C. Fusarium solani cutinase is a lipolytic enzyme with a catalytic serine accessible to solvent. Nature $1992 ; 356: 615-8$

45. VAN TILBEURGH H, SARDA L, VERGER R, CAMBILLAU C. Structure of the pancreatic lipaseprocolipase complex. Nature 1992; 359: 159-62.

46. VAN TILBEURGH H, EGLOFF M-P, MARTINEZ C, RUGANI N, VERGER R, CAMBILLAU C. Interfacial activation of the lipase-procolipase complex by mixed micelles revealed by X-Ray crystallography. Nature 1993 ; 362 : 814-20.

47. HAMOSH M. Lingual and gastric lipases: Their role in fat digestion. Boston : CRC Press, 1990.

48. HAMOSH M, GANOT D, HAMOSH P. Rat lingual lipase : Characteristics of enzyme activity. J Biol Chem 1979 ; 254 : 12121-5.

49. FIELD R, SCOW RO. Purification and characterization of rat lingual lipase. / Biol Chem 1983 ; $258: 14563-9$

50. ROBERTS IM, MONTGOMERY RK, CAREY MC Lingual lipase: Partial purification, hydrolytic properties and comparison with pancreatic lipase. Am J Physiol 1984 ; 247G : 385-93.

51. BODMER MW, ANGAL $S$, YARRANTON GT, ET AL. Molecular cloning of a human gastric lipase and expression of the enzyme in yeast. Biochim Biophys Acta 1987 ; 909 : 237-44.
52. MOREAU H, LAUGIER R, GARGOURI Y, FERRATO F, VERGER R. Human preduodenal lipase is entirely of gastric fundic origin. Gastroenterology $1988 ; 95$ : $1221-6$.

53. MOREAU H, BERNADAC A, GARGOURI Y, BENKOUKA F, LAUGIER R, VERGER R. Immunocytolocalisation of human gastric lipase in chief cells of the fundic mucosa. Histochemistry 1989; 91 : 419-23.

54. COHEN M, MORGAN RGH, HOFMANN AF. Lipolytic activity of human gastric and duodenal juice against medium and long chain triglycerides. Gastroenterology $1971 ; 60: 1-15$.

55. GARGOURI Y, PIERONI G, RIVIERE C, ET AL. Kinetic assay of human gastric lipase on shortand long-chain triacylglycerol emulsions. Gastroenterology 1986 ; 91 : 919-25.

56. ROGALSKA E, RANSAC S, VERGER R. Stereoselectivity of lipases. II. Stereoselective hydrolysis of triglycerides by gastric and pancreatic lipases. J Biol Chem 1990 ; 265 : 20271-6.

57. CARRIERE F, RAPHEL V, MOREAU H, ET AL. Dog gastric lipase: Stimulation of its secretion in vivo and cytolocalization in mucous pit cells. Gastroenterology 1992 ; 102 : 1535-45.

58. CARRIERE F, LAUGIER R, BARROWMAN JA, DOUCHET I, PRIYMENKO N, VERGER R. Gastric and pancreatic lipase levels during a test meal in dogs. Scand / Gastroenterol 1993 ; 28 : 443-54.

59. CARRIERE F, BARROWMAN JA, VERGER R, LAUGIER R. Secretion and contribution to lipolysis of gastric and pancreatic lipases during a test meal in humans. Gastroenterology 1993; 105 : 876-88.

60. LENGSFELD H, BEAUMIER-GALLON G, CHAHINIAN H, ET AL. Physiology of gastrointestinal lipolysis and therapeutical use of lipases and digestive lipase inhibitors. In: Müller $\mathrm{G}$, Petry S, eds. Lipases and phospholipases in drug development. Weinheim: Wiley-VCH, 2004 : 195-229.

61. CARRIERE F, RENOU C, LOPEZ V, ET AL. The specific activities of human digestive lipases measured from the in vivo and in vitro lipolysis of test meals. Gastroenterology 2000; 119 : 949-60.

62. CARRIERE F, GRANDVAL P, RENOU C, ET AL Quantitative study of digestive enzyme secretion and gastrointestinal lipolysis in chronic pancreatitis. Clin Gastroenterol Hepatol 2005 ; $3: 28-38$.

63. ROUSSEL A, MILED N, BERTI-DUPUIS L, ET AL. Crystal structure of the open form of dog gastric lipase in complex with a phosphonate inhibitor. J Biol Chem 2002 ; 277 : 2266-74.

64. ROUSSEL A, CANAAN S, EGLOFF MP, ET AL. Crystal structure of human gastric lipase and model of lysosomal acid lipase, two lipolytic enzymes of medical interest. / Biol Chem 1999 ; 274 : 16995-7002.
65. RANSAC S, GARGOURI Y, MOREAU H, VERGER R. Inactivation of pancreatic and gastric lipases by tetrahydrolipstatin and alkyl-dithio5-(2-nitrobenzoic acid). A kinetic study with 1,2-didecanoyl-sn-glycerol monolayers. Eur I Biochem $1991 ; 202$ : 395-400.

66. GARGOURI Y, CHAHINIAN H, MOREAU H, RANSAC S, VERGER R. Inactivation of pancreatic and gastric lipases by THL and C12:0-TNB : a kinetic study with emulsified tributyrin. Biochim Biophys Acta 1991 ; 1085 : 322-8.

67. CUDREY C, VAN TILBEURGH H, GARGOURI Y, VERGER R. Inactivation of pancreatic lipases by amphiphilic reagents 5-(Dodecyldithio)-2nitrobenzoic acid and tetrahydrolipstatin. Dependence upon partitioning between micellar and oil phases. Biochemistry 1993; 32 : 13800-8.

68. RANSAC S, GARGOURI Y, MARGUET F, ET AL. Covalent inactivation of lipases. Methods Enzymol $1997 ; 286$ : 190-231.

69. GARGOURI Y, ET AL. Covalent inhibition of digestive lipases: an in vitro study. Biochim Biophys Acta 1997 ; 1344 : 6-37.

70. TISS A, RANSAC S, LENGSFELD H, HADVARY $P$, CAGNA A, VERGER R. Surface behaviour of bile salts and tetrahydrolipstatin at air/water and oil/water interfaces. Chem Phys Lipids 2001 ; $111: 73-85$.

71. TISS A, LENGSFELD H, HADVARY P, CAGNA A, VERGER R. Transfer of orlistat through oil-water interfaces. Chem Phys Lipids 2002 ; 119 : 41-9.

72. TISS A, MILED N, VERGER R, GARGOURIY, ABOUSALHAM A. Digestive lipases inhibition: an in vitro study. In : Petry S, Müller $G$, eds. Lipases and phospholipases in drug development. Weinheim : Wiley-VCH, 2004 : 155-93.

73. CARRIERE F, RENOU C, RANSAC S, ET AL. Inhibition of gastrointestinal lipolysis by Orlistat during digestion of test meals in healthy volunteers. Am / Physiol Gastrointest Liver Physiol 2001 ; 281 : G16-G28.

74. BEN ALIY, CHAHINIAN H, PETRY S, ET AL. Might the kinetic behavior of hormonesensitive lipase reflect the absence of the lid domain? Biochemistry 2004 ; 43 : 9298-306.

75. BEN ALI Y, CHAHINIAN H, PETRY S, ET AL. Use of an Inhibitor To Identify Members of the Hormone-Sensitive Lipase Family. Biochemistry 2006 ; 45 : 14183-91.

76. CARRIÈRE F, MOREAU H, RAPHEL V, ET AL. Purification and biochemical characterization of dog gastric lipase. Eur J Biochem $1991 ; 202$ : 75-83.

77. BENICOURT C, BLANCHARD C, CARRIERE F, VERGER R, JUNIEN JL. Potential use of a recombinant dog gastric lipase as an enzymatic supplement to pancreatic extracts in cystic fibrosis. In : Escobar H, Baquero CF, Suárez L, eds. Clinical Ecology of Cystic Fibrosis. Amsterdam : Elsevier Science Publishers, 1993 : 291-5. 
78. GRUBER V, BERNA P, ARNAUD T, ET AL. Largescale production of a therapeutic protein in transgenic tobacco plants : effect of subcellular targeting on quality of a recombinant dog gastric lipase. Mol Breed $2001 ; 7$ : 329-40.

79. CHAHINIAN H, SNABE T, ATTIAS C, FOJAN P, PETERSEN SB, CARRIÈRE F. How gastric lipase an interfacial enzyme with a Ser-His-Asp catalytic triad - acts optimally at acidic $\mathrm{pH}$. Biochemistry 2006 ; 45 : 993-1001.

80. BELLE V, FOURNEL A, WOUDSTRA M, ET AL. Probing the opening of the pancreatic lipase lid using site-directed spin labeling and EPR spectroscopy. Biochemistry 2007 ; 46 : 2205-14.

81. HERMOSO J, PIGNOL D, PENEL S, ROTH M, CHAPUS C, FONTECILLA-CAMPS JC. Neutron crystallographic evidence of lipase-colipase complex activation by a micelle. EMBO / 1997 ; $16: 5531-6$.

82. HERMOSO J, PIGNOL D, KERFELEC B, CRENON I, CHAPUS C, FONTECILLA-CAMPS JC. Lipase activation by nonionic detergents. The crystal structure of the porcine lipase-colipasetetraethylene glycol monooctyl ether complex. | Biol Chem 1996 ; 271 : 18007-16.

83. DE CARO J, CARRIÈRE F, BARBONI P, GILLER T, VERGER R, DE CAROA. Pancreatic lipaserelated protein 1 (PLRP1) is present in the pancreatic juice of several species. Biochim Biophys Acta $1998 ; 1387$ : 331-41.

84. DE CARO I, SIAS B, GRANDVAL P, ET AL. Characterization of pancreatic lipase-related protein 2 isolated from human pancreatic juice. Biochim Biophys Acta 2004 ; 1701 : 89-99.
85. ROUSSEL A, DE CARO I, BEZZINE S, ET AL. Reactivation of the totally inactive pancreatic lipase RP1 by structure- predicted point mutations. Proteins $1998 ; 32: 523-31$

86. THIRSTRUP K, VERGER R, CARRIÈRE F. Evidence for a pancreatic lipase subfamily with new kinetic properties. Biochemistry 1994 ; 33 : 274856.

87. ANDERSSON L, CARRIÈRE F, LOWE M, NILSSON A, VERGER R. Pancreatic lipase-related protein 2 but not classical pancreatic lipase hydrolyzes galactolipids. Biochim Biophys Acta 1996 ; 1302 : 236-40.

88. DE CARO J, EYDOUX C, CHERIF S, ET AL. Occurrence of pancreatic lipase-related protein- 2 in various species and its relationship with herbivore diet. Comp Biochem Physiol B Biochem Mol Biol 2008 ; 150 : 1-9.

89. LOWE ME, KAPLAN MH, JACKSON-GRUSBY L, D'AGOSTINO D, GRUSBY MJ. Decreased neonatal dietary fat absorption and $\mathrm{T}$ cell cytotoxicity in pancreatic lipase-related protein 2-deficient mice. I Biol Chem 1998; 273: 31215-21.

90. SIAS B, FERRATO F, GRANDVAL P, ET AL. Human pancreatic lipase-related protein 2 is a galactolipase. Biochemistry 2004 ; 43 : 10138-48.

91. COTESK, DHOUIB R, DOUCHETI, ET AL Characterization of an exported monoglyceride lipase from Mycobacterium tuberculosis possibly involved in the metabolism of host cell membrane lipids. Biochem / 2007; 408: 417-27.
92. COTES K, BAKALA N'GOMAJC, DHOUIB R, ET AL. Lipolytic enzymes in Mycobacterium tuberculosis. Appl Microbiol Biotechnol 2008 ; $78: 741-9$.

93. FERNANDEZ S, JANNIN V, RODIER JD, RITTER N, MAHLER B, CARRIERE F. Comparative study on digestive lipase activities on the self emulsifying excipient Labrasol, medium chain glycerides and PEG esters. Biochim Biophys Acta $2007 ; 1771: 633-40$.

94. EGLOFF M-P, MARGUET F, BUONO G, VERGER R, CAMBILLAU C, VAN TILBEURGH H. The $2.46 \AA$ resolution structure of the pancreatic lipase-colipase complex inhibited by a $C_{11}$ alkyl phosphonate. Biochemistry 1995 ; 34 : 2751-62.

95. CHAHINIAN H, SIAS B, CARRIERE F. The C-terminal domain of pancreatic lipase : functional and structural analogies with c2 domains. Curr Protein Pept Sci 2000; 1 : 91-103.

96. CHAHINIAN H, BEZZINE S, FERRATO F, ET AL. The beta $5^{\prime}$ loop of the pancreatic lipase C2-like domain plays a critical role in the lipase-lipid interactions. Biochemistry $2002 ; 41$ : 13725-35.

97. BOURBON FREIE A, FERRATO F, CARRIERE F, LOWE ME. Val407 and lle408 in the? 5' Loop of Pancreatic Lipase Mediate Lipase-Colipase Interactions in the Presence of Bile Salt Micelles. | Biol Chem 2006 ; 281 : 7793-800.

98. WEIBEL EK, HADVÀRY $\mathrm{P}, \mathrm{HOCHULI} \mathrm{E}$, KUPFER E, LENGSFELD H. Lipstatin, an inhibitor of pancreatic lipase, produced by Streptomyces toxytricini. I. Producing organism, fermentation, isolation and biological acticity. / Antibiotics $1987 ; 40: 1801$. 